\title{
The effects of feeding rations that differ in fiber and fermentable starch within a day on milk production and the daily rhythm of feed intake and plasma hormones and metabolites in dairy cows
}

\author{
M. Niu, ${ }^{1}$ Y. Ying, P. A. Bartell, and K. J. Harvatine ${ }^{2}$ \\ Department of Animal Science, Penn State University, University Park 16802
}

\begin{abstract}
A daily pattern of feed intake, milk synthesis, and plasma metabolites and hormones occurs in dairy cows fed a total mixed ration once or twice a day. The objective of this study was to determine if feeding multiple rations within a day, complementing these rhythms, would improve milk production. Twelve Holstein cows were used in a replicated $3 \times 3$ Latin square design with 21-d periods. Cows were housed in tie stalls with feed tubs, and feed weight was recorded every $10 \mathrm{~s}$ for observation of feeding behavior. Rations were a low fiber and high fermentable starch ration [LFHS; $27.4 \%$ neutral detergent fiber (NDF) and $31.7 \%$ starch based on $55.7 \%$ corn silage and $14.1 \%$ steam-flaked corn], a high fiber and low fermentable starch ration (HFLS; $31.7 \%$ NDF and $22.3 \%$ starch based on $44 \%$ corn silage, $26.3 \%$ alfalfa haylage, and no steam-flaked corn), and a total mixed ration that was a 1:3 ratio of LFHS and HFLS (30.7\% NDF, $24.5 \%$ starch). The control treatment $(\mathrm{CON})$ cows were fed the total mixed ration at $0700 \mathrm{~h}$, the high/low treatment (HL) fed HFLS ration at $0700 \mathrm{~h}$ and LFHS ration at $2200 \mathrm{~h}$, and the low/ high (LH) treatment fed LFHS ration at $0700 \mathrm{~h}$ and HFLS ration at $1100 \mathrm{~h}$ (LFHS and HFLS rations fed at a 1:3 ratio). No effect was found of treatment on daily milk, but LH decreased milk fat concentration and yield compared with HL (0.2 percentage units and $0.24 \mathrm{~kg}$, respectively). Daily dry matter and NDF intake and total-tract digestibility did not differ between treatments. The HL treatment reduced intake at the morning-conditioned meal after feeding and reduced intake before the evening feeding. A treatment by time of day interaction was found for fecal NDF and indigestible NDF concentration, blood urea nitrogen (BUN), plasma insulin, and fatty acid concentration, and body temperature. The CON and LH treatments increased

Received March 3, 2016

Accepted September 23, 2016.

${ }^{1}$ Current address: Department of Animal Science, University of California, Davis.

${ }^{2}$ Corresponding author: kjh182@psu.edu
\end{abstract}

the daily amplitude of fecal NDF by 1.0 and 1.1 percentage units compared with HL. Plasma insulin was higher in HL than CON at 0100 and $0400 \mathrm{~h}$, but lower at 1300 and $1900 \mathrm{~h}$. Plasma fatty acids were higher for CON than HL at $0700 \mathrm{~h}$ and HL was lower than LH at 0400 and $1900 \mathrm{~h}$. Plasma BUN was higher for HL than control at $0100 \mathrm{~h}$, but lower at $1000 \mathrm{~h}$. Body temperature in CON and HL treatments followed a similar diurnal pattern, whereas body temperature for LH was lower than that of HL treatment at 1300 and $2300 \mathrm{~h}$. No daily rhythm was found of fecal indigestible NDF concentration, plasma glucose, or fatty acids detected in the HL treatment, and the amplitude of plasma insulin and BUN was lower for HL compared with CON (70 and $60 \%$ decrease, respectively). In conclusion, feeding 2 rations that differ in fiber and fermentable starch modifies diurnal rhythms in dairy cows. Furthermore, feeding a high fiber and low fermentable starch ration during the high intake period of the day may stabilize nutrient absorption across the day.

Key words: circadian, diurnal, feed intake, milk fat

\section{INTRODUCTION}

Circadian rhythms are repeating 24 -h cycles exhibited by most physiological functions in animals and these rhythms are entrained by numerous environmental cues including strong entrainment by light-dark cycles and entrainment by feed availability in some situations (see review by Schibler et al., 2003). Giannetto and Picciano (2009) reported that 12 of 25 variables observed in dairy cows followed a circadian pattern. Additionally, circadian rhythms in plasma cortisol, growth hormone, insulin, fatty acids, BUN, locomotor activity, and body temperature of dairy cows have been reported (Lefcourt et al., 1995, 1999; Giannetto and Picciano, 2009).

Daily rhythmicity of feed intake has been well described including conditional meals related to feed delivery and a daily pattern of spontaneous meals with higher intake during the afternoon and lower intake during the overnight period (e.g., DeVries et al., 2005). Total mixed rations are a feeding technology developed 
more than $30 \mathrm{yr}$ ago and are widely used in the dairy industry. The advantage of TMR feeding is that it supplies a consistent ration composition at each meal, with the goal of reducing fluctuations in the entry of rapidly fermentable substrate into the rumen across the day (Coppock et al., 1981). However, ruminal fermentation of cows fed TMR is not consistent because the daily pattern of feeding across the day results in fluctuations in starch entry into the rumen and rumen digesta composition (e.g., Ying et al., 2015). Specifically, the natural daily pattern of intake results in a higher flux of fermentable substrate entering the rumen during the higher intake period, and a lower flux of fermentable substrate entering the rumen during the lower intake period. This variation in intake combined with the large differences in the rate of digestion of starch and fiber results in ruminal digesta being higher in starch during the active feeding period of the day and lower in starch overnight. Additionally, Fickett and Allen (2002) reported lower ruminal amylolytic capacity before feeding compared with after feeding in cows fed a TMR once per day.

Rottman et al. (2015) investigated the effect of feeding 2 rations differing in forage to concentrate ratio at different times within a day in an attempt to complement the daily pattern of intake and stabilize rumen fermentation and reported that feeding a low forage diet in the morning increased feed efficiency and milk fat yield compared with feeding the low forage diet at night, presumably because of a priming effect allowing a more rapid increase in rumen starch from the low levels overnight. Feeding a high forage diet in the morning and a low forage diet at night unexpectedly reduces DMI and reduced milk fat yield. The objective of the current study was to determine the effect of offering 2 rations differing in both fiber and fermentable starch concentration during the high intake or low intake periods of the day on milk production and the daily rhythm of feed intake and key plasma hormones and metabolites. The hypothesis was that feeding a higher fiber and lower fermentable starch ration during the high intake period of the day would stabilize rumen fermentation and the circadian rhythms of plasma metabolites and metabolic hormones, whereas feeding a low fiber and high fermentable starch ration during the high intake period of the day would have the opposite effect.

\section{MATERIALS AND METHODS}

\section{Experimental Design and Treatments}

The experiment was conducted from April to May of 2012 at the Pennsylvania State University Dairy Pro- duction Research and Teaching Center. Twelve noncannulated multiparous Holstein cows $(2.5 \pm 0.21$ parities; $128 \pm 8$ DIM; mean $\pm \mathrm{SD}$ ) were housed in a tie-stall barn with mattresses and sawdust bedding and randomly assigned to treatment sequences in a replicated $3 \times 3$ Latin square design with 21 -d periods (sequenced balanced for carry-over effects). One cow was removed at beginning of the experiment due to mastitis. Rations were a low fiber and high fermentable starch ration (LFHS; $27.4 \%$ NDF, $31.7 \%$ starch, $55.7 \%$ corn silage, and $14.1 \%$ steam-flaked corn), a high fiber and low fermentable starch ration (HFLS; $31.7 \%$ NDF, $22.3 \%$ starch, $44 \%$ corn silage, and no steam-flaked corn), and a control TMR that was a 1 to 3 ratio of LFHS to HFLS. The 3 treatments were feeding (1) the control TMR at $0700 \mathrm{~h}(\mathbf{C O N}),(2)$ HFLS ration at $0700 \mathrm{~h}$ and LFHS ration at $2200 \mathrm{~h}(\mathbf{H L})$, or (3) LFHS ration at $0700 \mathrm{~h}$ and HFLS ration at $1100 \mathrm{~h}(\mathbf{L H})$. The LFHS and HFLS rations were offered in a 1 to 3 ratio, respectively. The 7-h starch fermentability of ground corn was 45.4 , steam-flaked corn was $69.8 \%$, and corn silage was $73.6 \%$. The control TMR (1:3 ratio of LFHS:HFLS) was formulated to meet or exceed NRC (2001) recommendations. Although formulated for equal CP, the HFLS ration was 0.7 percentage units higher than the LFHS ration, but both are above expected RDP requirements (Table 1). A NPN source was used in the LFHS ration to balance for the NPN found in alfalfa haylage in the HFLS ration.

Cows were individually fed ad libitum at $110 \%$ of expected daily intake. All rations were mixed at 0600 $\mathrm{h}$, stored at ambient temperature compacted in plastic bins, and covered with plastic to reduce exposure to air. Refused feed was removed and weighed once per day before feed delivery at $0700 \mathrm{~h}$ in all treatments. A light-sensing data logger verified a consistent $18 \mathrm{~h}$ of light to $6 \mathrm{~h}$ of dark schedule (dark $\sim 2300$ to $0500 \mathrm{~h}$ ) and environmental temperature averaged $18.7 \pm 4.8^{\circ} \mathrm{C}$ (mean $\pm \mathrm{SD})$.

\section{Data and Sample Collection and Analysis}

Nine cows were housed in tie stalls equipped with a feed intake observation system using feed tubs hanging from load cells as described by Niu et al. (2014). Briefly, feed weight was recorded every $10 \mathrm{~s}$ from d 15 to 21 of each period. Feed intake over 2-h intervals over the day was calculated based on running averages. Meals were determined through a multi-step process. The running average and standard deviation of the feed tub weight was determined over 2 min ever $10 \mathrm{~s}$. First, possible eating activity was flagged when the running standard deviation of feed weight was greater than the 80th percentile. Meal size was determined based on the stable 
Table 1. Ingredient and chemical composition of experimental rations

\begin{tabular}{|c|c|c|c|}
\hline \multirow[b]{2}{*}{ Item } & \multicolumn{3}{|c|}{ Ration $^{1}$} \\
\hline & Control & HFLS & LFHS \\
\hline \multicolumn{4}{|l|}{ Ingredient, $\%$ of $\mathrm{DM}$} \\
\hline Corn silage $^{2}$ & 46.8 & 44.0 & 55.7 \\
\hline Alfalfa haylage ${ }^{3}$ & 20.1 & 26.3 & - \\
\hline Canola meal & 7.4 & 6.6 & 10.0 \\
\hline Roasted sovbeans & 7.2 & 7.1 & 7.7 \\
\hline Bakery byproduct & 5.8 & 5.7 & 6.1 \\
\hline Ground $\operatorname{corn}^{4}$ & 3.6 & 4.7 & - \\
\hline Steam-flaked corn ${ }^{5}$ & 3.3 & - & 14.1 \\
\hline Molasses & 2.9 & 2.8 & 3.1 \\
\hline Vitamin-mineral $\operatorname{mix}^{6}$ & 2.3 & 2.3 & 2.4 \\
\hline $\mathrm{NPN}^{7}$ & 0.5 & 0.3 & 0.9 \\
\hline \multicolumn{4}{|c|}{ Chemical composition, ${ }^{8} \%$ of DM } \\
\hline $\mathrm{CP}$ & 16.8 & 17.0 & 16.3 \\
\hline NDF & 30.7 & 31.7 & 27.4 \\
\hline $\mathrm{ADF}$ & 20.7 & 22.1 & 16.2 \\
\hline Starch & 24.5 & 22.3 & 31.7 \\
\hline Ash & 6.0 & 6.5 & 4.6 \\
\hline \multicolumn{4}{|l|}{ Particle size, $\%$} \\
\hline$>19.0 \mathrm{~mm}$ & 2.8 & 3.5 & 1.5 \\
\hline 19.0 to $8 \mathrm{~mm}$ & 53.8 & 51.8 & 45.5 \\
\hline 8 to $1.18 \mathrm{~mm}$ & 35.5 & 36.0 & 41.8 \\
\hline$<1.18$ & 7.9 & 8.7 & 11.1 \\
\hline Mean, cm & 0.66 & 0.65 & 0.56 \\
\hline
\end{tabular}

${ }^{1}$ Control is a 1:3 mixture of the high fiber and low fermentable starch ration (HFLS) and a low fiber and high fermentable starch ration (LFHS).

${ }^{2}$ Contained $37.8 \% \mathrm{DM}$ and $8.5 \% \mathrm{CP}, 37.8 \% \mathrm{NDF}$, and $34.3 \%$ starch on a DM basis and 7-h starch digestibility was $73.6 \%$.

${ }^{3}$ Contained $41.0 \% \mathrm{DM}$ and $21.4 \% \mathrm{CP}, 40.4 \% \mathrm{NDF}$, and $1.3 \%$ starch on a DM basis.

${ }^{4} 68.3 \%$ starch and 7 -h starch digestibility of $45.4 \%$.

${ }^{5} 77.9 \%$ starch and 7 -h starch digestibility of $69.8 \%$.

${ }^{6}$ Contained (\%, as-fed basis): 45.8 dried corn distillers grains with solubles; 35.8 limestone (38\% Ca); 8.3 magnesium oxide $(54 \% \mathrm{Mg}$ ); 6.4 salt; 1.73 vitamin ADE premix; 1.09 selenium premix (0.06\% selenium): and 0.88 trace mineral mix. Composition (DM basis): $11 \% \mathrm{CP}$ $18 \%$ NDF; $5.2 \%$ fat; $14.9 \%$ Ca; $0.35 \%$ P; $4.58 \% \mathrm{Mg} ; 0.41 \% \mathrm{~K} ; 0.31 \%$ $\mathrm{S} ; 357 \mathrm{mg} / \mathrm{kg}$ of $\mathrm{Cu} ; 1,085 \mathrm{mg} / \mathrm{kg}$ of Zn; $181 \mathrm{mg} / \mathrm{kg}$ of Fe; $6.67 \mathrm{mg} / \mathrm{kg}$ of Se; $125,875 \mathrm{IU} / \mathrm{kg}$ of vitamin A (retinyl acetate); 31,418 IU $/ \mathrm{kg}$ of vitamin D (activated 7-dehydrocholesterol); and $946 \mathrm{IU} / \mathrm{kg}$ of vitamin E (DL- $\alpha$ tocopheryl acetate). Purchased from Cargill Animal Nutrition (Minneapolis, MN).

${ }^{7}$ Coated urea (Optigen; Alltech Inc., Lexington, $\mathrm{KY} ; 256 \% \mathrm{CP}$ on a DM basis).

${ }^{8}$ Analyzed by Cumberland Valley Analytical Services (Hagerstown, MD).

feed weight before and after the eating flag. Minimal meal size was $0.45 \mathrm{~kg}$ of DM. The minimal intermeal interval used was 8 min as previously determined based on the distribution of the log-transformed intervals as described by Tolkamp and Kyriazakis (1999) in a similar feed observation system that also included chew halters (Harvatine and Allen, 2006). The minimum meal interval was determined to be 10 min for CON cows in the current experiment using the approach of Tolkamp and Kyriazakis (1999). Only 2.2\% of the meal intervals were between 8 and $10 \mathrm{~min}$, so feeding behavior data were not reanalyzed. A minimum interval could not be determined for each cow because of the limited number of observation days in the experiment. Eating time does not include intermeal intervals less than $8 \mathrm{~min}$ (idle time within meals). Eating rate is DMI within meal divided by eating time within meal (not including idle time within meal).

Each ration and individual feed ingredients were sampled on d 15, 18, and 21 and orts (12.5\%) were sampled before the morning feeding from d 15 to 21 of each period. Feed and orts samples were composited by period. Forages and a mix of concentrate feeds representing what was mixed were analyzed for DM, NDF, indigestible NDF (iNDF; $240 \mathrm{~h}$ in vitro), CP, and ash by wet chemistry procedures [Cumberland Valley Analytical Services Inc., Hagerstown, MD] and starch concentration by an enzymatic method according to (Karkalas, 1985). Orts samples were analyzed for DM, NDF, and ash by the same procedures.

Cows were milked twice daily at 0500 and $1700 \mathrm{~h}$ and milk yield determined by an integrated milk meter (AfiMilk; SAE Afikim, Israel) and analyzed as the average of d 20 and 21 of each period. Milk was sampled at both milkings on d 20 and 21 of each period and analyzed for fat (filter B) and true protein by infrared spectroscopy (Dairy One Lab, State College, PA). Milk fatty acid profile was determined by GLC at each milking on d 21 (Rico and Harvatine, 2013).

Blood samples were collected every $9 \mathrm{~h}$ from d 19 to 21 of each period $(0100,0400,0700,1000,1300,1600$, 1900 , and $2200 \mathrm{~h}$ ). Plasma samples were analyzed for insulin (Coat-a-count insulin kit; Siemens Healthcare Diagnostics, Los Angeles, CA), glucose (PGO Enzyme procedure no. P 7119; Sigma-Aldrich, St. Louis, MO), BUN [Modified Enzymatic Urea Nitrogen (Procedure No. 2050); Stanbio Laboratory, Boerne, TX], and fatty acids [Wako HR Series NEFA-HR kit (Wako Chemicals USA Inc., Richmond, VA) as modified by Ballou et al. (2009)].

Plasma samples were analyzed for insulin, glucose, BUN, and fatty acids (Rottman et al., 2014). Fecal grab samples were also collected at the same time as blood sampling and fecal NDF and iNDF (240 h in vitro) were measured on all samples (Cumberland Valley Analytical Services Inc.). Total-tract digestibility was determined using iNDF.

Core body temperature was recorded every $10 \mathrm{~min}$ from d 15 to 21 of each period using an intra-vaginal temperature probe (iBCod; Alpha Mach Inc., MontSt.-Hilaire, QC, Canada) as previously described (Niu et al., 2014). 


\section{Statistical Analysis}

Feeding behavior, plasma metabolites and hormones, body temperature, lying activity, and fecal NDF and iNDF concentration were statistically analyzed using the MIXED procedure of SAS with repeated measures (version 9.3, SAS Institute Inc., Cary, NC). The model included the random effects of sequence, period, and cow nested in sequence and the fixed effect of treatment, time (variable depending on variable), and the interaction of treatment and time. The $\operatorname{AR}(1)$ and $\mathrm{ARH}(1)$ covariance structures were used based on model fit, time of day was the repeated variable, and cow by treatment was the subject. The preplanned contrasts were between CON and HL and between HL and LH at each time point and denominator degrees of freedom were adjusted by the Kenward-Roger method. Parameters averaged over the day were analyzed with a reduced model that did not include the effect of time using JMP (version 9.4, SAS Institute Inc.). Significance was declared at $P<0.05$ and tendencies at $P<$ 0.10 .

Second, time course data were then fit to a cosine function with a 24 -h period for circadian rhythm analysis using the linear form of the cosine function in Proc Mixed as described by Niu et al. (2014). A zero amplitude $F$-test comparing the cosine fit to a linear fit was used to determine the significance of fit for each treatment. The preplanned contrasts tested the differences in amplitude and acrophase (report as time at peak).

\section{RESULTS}

\section{Milk Production and Milk Fatty Acids}

No effect was observed of treatment on daily yield of milk, milk protein, or on milk protein concentration. However, LH decreased milk fat concentration and yield compared with HL (0.24 percentage units and $0.23 \mathrm{~kg} ; P<0.01$ and $P=0.04$; Table 2). A treatment by milking interaction was found for milk fat concentration $(P=0.03$; Table 2$)$ as milk fat was 0.20 and 0.32 percentage units higher in HL compared with $\mathrm{CON}$ and LH treatments, respectively, at the $0500 \mathrm{~h}$ milking. No treatment by milking interactions were found for the yield or composition of other milk components (Table 2 and Supplemental Table S1; https://doi.org/10.3168/ jds.2016-11129).

Daily average concentrations of trans-10 C18:1 and trans-11 C18:1, and de novo, total 16C, and preformed fatty acids were not affected by treatment (Table 2); however, the LH treatment tended to increase cis9,trans-11 CLA by 0.05 percentage units compared with HL $(P=0.06$; Table 2$)$. A treatment by milking interaction was found for trans-10 C18:1 $(P<0.01$; Supplemental Table S2; https://doi.org/10.3168/ jds.2016-11129) as trans-10 C18:1 was 0.04 percentage units higher at the $0500 \mathrm{~h}$ milking for both CON and LH compared with HL $(P=0.03$ and $P=0.02$, respectively). The LH treatment also tended to increase cis-9, trans-11 CLA during the $0500 \mathrm{~h}$ milking compared with HL $(P=0.08)$, whereas LH tended to decreased 16C fatty acids during the $1700 \mathrm{~h}$ milking compared with HL $(P=0.08)$.

\section{Feed Intake and Feeding Patterns}

The time between feed offerings differed in the $\mathrm{LH}$ and HL treatments based on the expected eating rate during the morning and overnight periods of the day (Niu et al., 2014). The selected timing performed well, although some cows consumed the LFFS ration faster than expected in the LH treatment. No effect was found of treatment on daily DM or NDF intake or total-tract digestibility (Table 3). A treatment by time interaction was observed for feed intake as a percent of daily intake over the day $(P<0.01$; Figure 1$)$, which was lower for HL compared with CON from 0800 and 1200 to 2000 $\mathrm{h}$, but higher at $2200 \mathrm{~h}$ when the LFHS ration was fed $(P<0.05)$. Feed intake was higher in LH than HL at $0800 \mathrm{~h}$ after feeding of the LFHS ration, was lower in LH than HL at $1000 \mathrm{~h}$, but was again higher at 1200 $\mathrm{h}$ following offering of the HFLS ration. Feed intake over 30-min intervals is provided in Supplemental Figure S1 (https://doi.org/10.3168/jds.2016-11129), and although it provides a higher resolution, the interpretation of treatment response is similar to the 2-h intervals. The rate of feed intake during spontaneous feeding periods fit a cosine function with a 24 -h period in all treatments $(P<0.01$; Table 5$)$. The acrophase for HL $(1425 \mathrm{~h})$ was advanced compared with CON (1602 h; $P$ $<0.05)$ and LH (1759 h; $P<0.05)$. The amplitude of CON and LH was increased by 0.2 and 0.8 percentage units per h compared with HL, respectively $(P<0.05)$.

Starch and NDF intake was determined based on intake and composition of diet fed. Because the LFHS and HFLS diets differed in NDF and starch levels, the daily pattern of NDF and starch intake differ from the daily pattern of DMI. The NDF intake was lower in HL than CON at $0800 \mathrm{~h}$, but was higher at $2200 \mathrm{~h}$ when rapid intake of the LFHS diet occurred (Figure 1). The NDF intake was also lower in HL than HL at 0800 and $1200 \mathrm{~h}$ when feeding of LFHS and HFLS diets occurred. Starch intake was lower in HL than $\mathrm{LH}$ and $\mathrm{CON}$ at $0800 \mathrm{~h}$ and was almost $1.5 \mathrm{~kg} / \mathrm{h}$ higher in HL compared with CON and LH at $2200 \mathrm{~h}$ with feeding of the LFHS diet. The actual pattern of starch and NDF intake may 
Table 2. The effect of feeding a single TMR or feeding 2 rations within a day that differ in fiber and fermentable starch concentration on daily milk and milk component yield, milk composition, and selected milk fatty acids (FA)

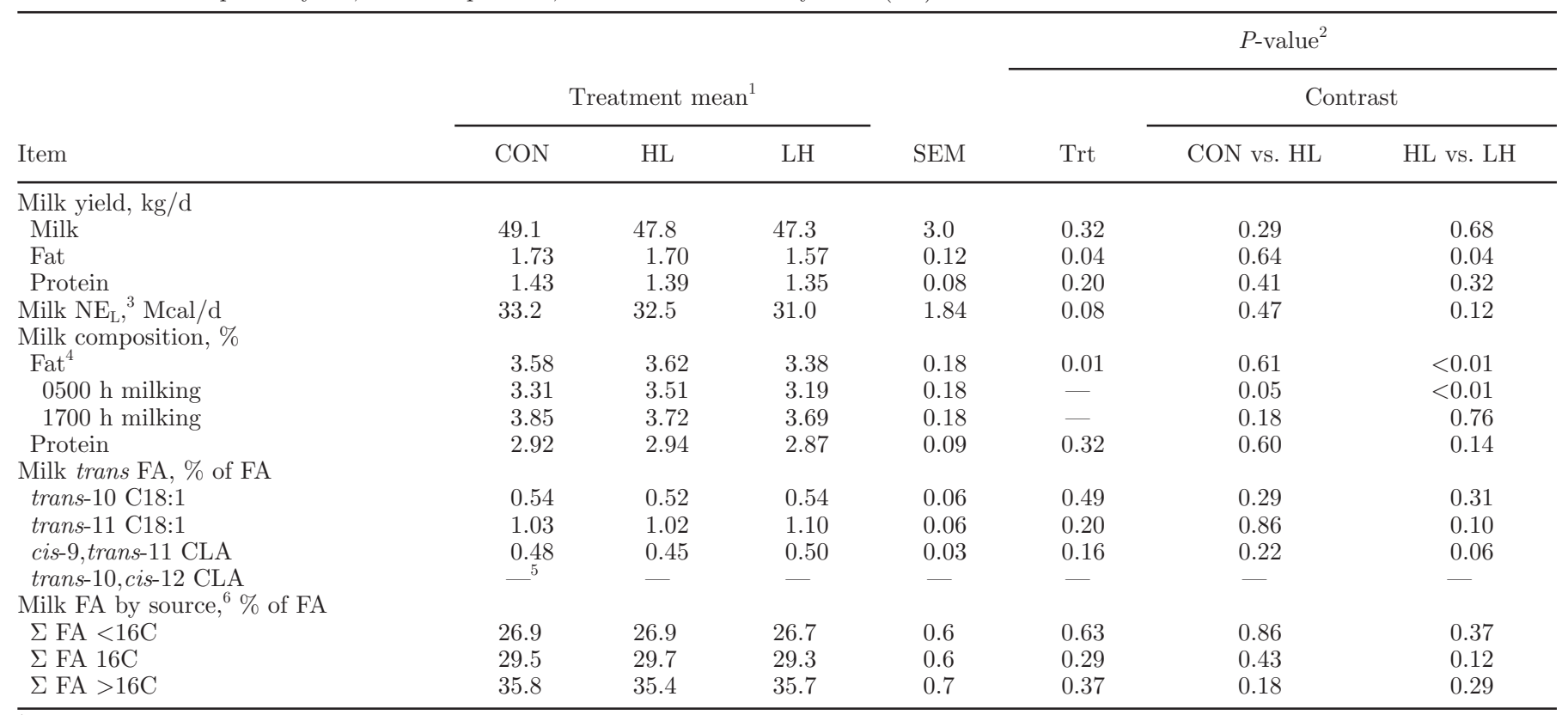

${ }^{1}$ Least squares means. Control (CON) was fed a TMR that was a 1:3 mix of a low fiber and high fermentable starch ration (LFHS) and high forage and low fermentable starch ration (HFLS) at $0700 \mathrm{~h}$, the high/low treatment (HL) was fed HFLS at $75 \%$ of daily offering at $0700 \mathrm{~h}$ and a LFHS ration at $25 \%$ of daily offering at $2200 \mathrm{~h}$, and the low/high treatment (LH) was fed LFHS ration at $25 \%$ of daily offering at $0700 \mathrm{~h}$ and HFLS ration at $75 \%$ of daily offering at $1100 \mathrm{~h}$.

${ }^{2}$ Effect of treatment and preplanned contrasts.

${ }^{3}$ Calculated by NRC (2001) using equation 2-16.

${ }^{4}$ Significant treatment by milking interaction for milk fat $(P=0.03)$. Means at each milking are shown.

${ }^{5}$ Below the level of detection.

${ }^{6}$ Fatty acids $<16 \mathrm{C}$ originate from the mammary gland (C15:0 is not included); FA $>16 \mathrm{C}$ originate from plasma; 16C FA originate from both sources.

be slightly different as we are unable to account for differences in sorting across time.

Feeding behavior was also analyzed based on meal criteria. The number of meal bouts per day was decreased 0.9 meals per day in LH compared with the HL treatment $(P=0.05$; Table 3$)$. The HL treatment tended to increase eating rate $(P=0.06)$ and decrease eating time $(P=0.08)$ compared with CON, but HL did not differ from LH treatment. Average meal length for LH treatment was longer than HL cows (41.7 vs. $37.2 \mathrm{~min} /$ meal; $P=0.03$ ) and average meal size was $0.9 \mathrm{~kg}$ larger for LH compared with HL $(P<0.01)$. The inter-meal interval for CON and LH was 23.1 and 20.4 min longer than HL treatment, respectively $(P<0.05)$.

Meal parameters were also analyzed for both the LFHS and HFLS rations when fed at different times of day in the HL and LH treatments (Table 4). A treatment by ration interaction was found for meal size and meal interval $(P<0.01)$. Meal size was $1.9 \mathrm{~kg}$ larger in the LFHS diet when fed in the morning in the LH treatment compared with the evening in the HL treatment; however, intake of the HFLS diet was similar be- tween treatments. Inter-meal interval was over $65 \mathrm{~min}$ longer in the LFHS diet when fed in the HL treatment compared with the LH treatment.

\section{Fecal Concentration of NDF and iNDF}

A treatment by time interaction was found for fecal NDF (\% of DM) and iNDF (\% of NDF) concentration $(P=0.04$ and 0.09 , respectively; Figure 2). Fecal NDF concentration for $\mathrm{CON}$ and $\mathrm{LH}$ gradually increased after $1000 \mathrm{~h}$ and reached a peak at $1900 \mathrm{~h}$. Fecal NDF was higher for CON and LH compared with HL treatment at $1900 \mathrm{~h}(P<0.01)$, whereas HL was higher than LH treatment at $0100 \mathrm{~h}(P<0.05)$. Fecal iNDF as a percent of NDF was higher for HL from 0700 to 1000 h compared with LH $(P<0.05)$, and higher at $1000 \mathrm{~h}$ compared with CON $(P<0.05)$. Also, HL tended to increase iNDF proportion of NDF at $0400 \mathrm{~h}$ compared with LH $(P=0.08)$, and at $0700 \mathrm{~h}$ compared with CON $(P=0.08)$.

A cosine function with a $24-\mathrm{h}$ period fit fecal NDF for all treatments (Table 5). The acrophase for HL (2128 
h) was advanced compared with CON (1813 h; $P<$ $0.05)$ and LH (1643 h; $P<0.05)$. The amplitude of CON and LH was increased by 1.0 and 1.1 percentage units compared with HL, respectively $(P<0.05)$. The cosine function fit iNDF as a percent of NDF for CON and LH treatments $(P<0.01$; Table 5$)$, but the cosine function failed to fit HL.

\section{Key Plasma Metabolites and Metabolic Hormones}

No treatment by time interaction was found for plasma glucose, but a main effect of treatment was observed. Plasma glucose concentration was lower in HL than CON at $1000 \mathrm{~h}(P<0.05$; Figure $3 \mathrm{~A})$ and HL tended to be lower than LH at 0100 and $1000 \mathrm{~h}$ $(P<0.10)$. Only plasma glucose concentration for $\mathrm{LH}$ fit a cosine function, with an acrophase at $0547 \mathrm{~h}$ and amplitude of $2.8 \mathrm{mg} / \mathrm{dL}(P=0.03$; Table 5$)$.

A treatment by time interaction was found for plasma insulin $(P<0.001$; Figure 3B), which was higher in HL than CON at 0100 and $0400 \mathrm{~h}$, but lower at 1300 and $1900 \mathrm{~h}(P<0.05)$. The HL treatment tended to decrease insulin compared with $\mathrm{CON}$ at $1600 \mathrm{~h}(P=$ 0.06). Insulin was higher for HL than LH from 0100 through $0400 \mathrm{~h}$, but lower at $1900 \mathrm{~h}$ compared with LH $(P<0.05)$. Insulin fit a cosine function with a 24 -h period in all treatments $(P<0.05$; Table 5$)$. Acrophase was phase delayed by HL $(1929 \mathrm{~h})$ and $\mathrm{LH}$ $(1739 \mathrm{~h})$ compared with CON (1650 h; $P<0.05)$, and
HL decreased the amplitude of insulin concentration compared with CON and LH $(P<0.05)$.

A treatment and time interaction was detected for plasma fatty acids $(P=0.01$; Figure $3 \mathrm{C})$, as plasma fatty acids were higher for CON than HL at $0700 \mathrm{~h}$ $(P<0.01)$ and HL was lower than LH at 0400 and $1900 \mathrm{~h}(P<0.05)$. Plasma fatty acids for CON and LH treatments fit a cosine function with a 24 -h period $(P<0.01$; Table 5$)$; however, fatty acid concentration failed to fit the cosine function in the HL treatment. The CON and LH treatment acrophases occurred at 0621 and $0421 \mathrm{~h}$ and amplitude peaked at 10.2 and 13.1 $\mu \mathrm{Eq} / \mathrm{L}$, respectively.

A treatment by time interaction was observed for BUN $(P=0.002$; Figure 3D), which was higher for HL than $\mathrm{CON}$ at $0100 \mathrm{~h}$, but lower at $1000 \mathrm{~h}(P<0.05)$. Blood urea nitrogen fit a cosine function with a 24 -h period in all treatments $(P<0.01$; Table 5$)$. The acrophase of CON (1240 h) was delayed by more than $2 \mathrm{~h}$ by HL, and the acrophase of LH (1041 h) differed from the HL treatment $(1529 \mathrm{~h} ; P<0.05)$. The amplitude for HL was 1.2 and $0.3 \mathrm{mg} / \mathrm{dL}$ lower than CON and LH treatment, respectively $(P<0.05)$.

\section{Body Temperature}

Body temperature normally follows a circadian pattern in synchrony with the central timekeeper. Body temperature in CON and HL treatments followed a

Table 3. The effect of feeding a single TMR or feeding 2 rations within a day that differ in fiber and fermentable starch concentration on daily DMI, total-tract digestibility, and meal parameters in lactating cows

\begin{tabular}{|c|c|c|c|c|c|c|c|}
\hline Item & \multicolumn{3}{|c|}{ Treatment mean $^{1}$} & SEM & \multicolumn{3}{|c|}{$P$-value } \\
\hline \multicolumn{8}{|l|}{$\mathrm{DM}$} \\
\hline Intake, ${ }^{3} \mathrm{~kg} / \mathrm{d}$ & 27.7 & 28.1 & 27.7 & 2.6 & 0.67 & 0.45 & 0.44 \\
\hline Digestibility, \% & 71.3 & 71.1 & 70.9 & 1.3 & 0.44 & 0.50 & 0.54 \\
\hline Digestibility, \% & 47.6 & 47.9 & 47.3 & 2.8 & 0.66 & 0.64 & 0.37 \\
\hline \multicolumn{8}{|l|}{ Meal } \\
\hline Bouts/d & 10.7 & 11.1 & 10.2 & 0.6 & 0.13 & 0.35 & 0.05 \\
\hline Size, $\mathrm{kg}$ of $\mathrm{DM} / \mathrm{meal}$ & 2.7 & 3.1 & 4.0 & 0.3 & $<0.01$ & 0.12 & $<0.01$ \\
\hline Length, min/meal & 37.5 & 37.2 & 41.7 & 1.7 & 0.05 & 0.88 & 0.03 \\
\hline Interval, min & 84.4 & 107.5 & 87.1 & 13.2 & 0.01 & $<0.01$ & 0.01 \\
\hline Eating time ${ }^{4} \mathrm{~min} / \mathrm{d}$ & 328.0 & 314.8 & 314.7 & 10.5 & 0.12 & 0.08 & 0.98 \\
\hline
\end{tabular}

${ }^{1}$ Least squares means. Control (CON) was fed a TMR that was a 1:3 mix of a low fiber and high fermentable starch ration (LFHS) and high forage and low fermentable starch ration (HFLS) at $0700 \mathrm{~h}$, the high/low treatment (HL) was fed HFLS at $75 \%$ of daily offering at $0700 \mathrm{~h}$ and a LFHS ration at $25 \%$ of daily offering at $2200 \mathrm{~h}$, and the low/high treatment (LH) was fed LFHS ration at $25 \%$ of daily offering at $0700 \mathrm{~h}$ and HFLS ration at $75 \%$ of daily offering at $1100 \mathrm{~h}$.

${ }^{2}$ Effect of treatment and preplanned contrasts.

${ }^{3} 55^{\circ} \mathrm{C}$ DMI.

${ }^{4}$ Eating time does not include idle time within meals. Eating rate is intake divided by eating time. 
similar diurnal pattern, whereas body temperature for LH was lower than that of HL treatment at 1300 and $2300 \mathrm{~h}(P<0.05)$ and tended to lower from 1900
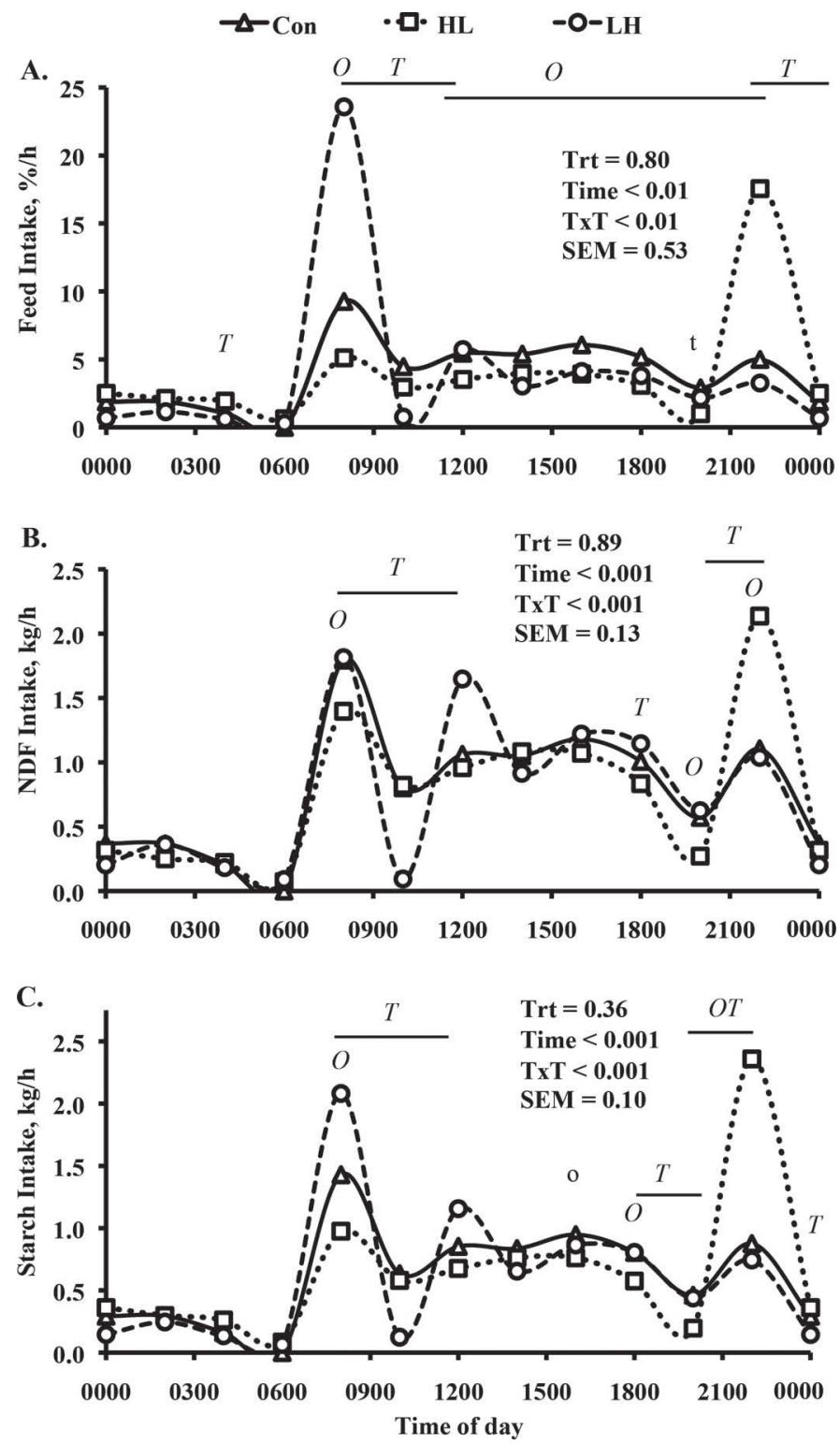

Figure 1. The effect of feeding a single TMR or feeding 2 rations within a day that differ in fiber and fermentable starch concentration on the daily rhythm of feed intake as a percentage of total daily intake (A), and NDF (B) and starch (C) as kilograms per hour over 2-h intervals. Control (Con) was fed a TMR that was a 1:3 mix of a low fiber and high fermentable starch ration (LFHS) and high forage and low fermentable starch ration (HFLS) at $0700 \mathrm{~h}$, the high/low treatment (HL) was fed HFLS at $75 \%$ of daily offering at $0700 \mathrm{~h}$ and a LFHS ration at $25 \%$ of daily offering at $2200 \mathrm{~h}$, and the low/high treatment (LH) was fed a LFHS ration at $25 \%$ of daily offering at $0700 \mathrm{~h}$ and HFLS ration at $75 \%$ of daily offering at $1100 \mathrm{~h}$. The effect of treatment (Trt), time, and their interaction (TxT) are shown within the panel. Preplanned contrasts tested the difference between Con and HL $\left({ }^{O} P\right.$ $<0.05$, and $\left.{ }^{\circ} P<0.1\right)$, and between HL and LH $\left({ }^{T} P<0.05\right.$, and ${ }^{t} P<$ $0.1)$. Light and dark phases are shown. through $2100 \mathrm{~h}(P<0.10 ;$ Figure 4$)$. Generally, a small peak was observed at approximately $0900 \mathrm{~h}$ and a larger peak was observed at approximately $2100 \mathrm{~h}$ in all treatments. Cosinor rhythmicity was detected for all treatments $(P<0.01$; Table 5$)$. The acrophase of $\mathrm{CON}$ $(0953 \mathrm{~h})$ and LH $(1056 \mathrm{~h})$ differed from HL $(1020 \mathrm{~h} ; P$ $<0.05)$. The amplitudes of $\mathrm{CON}$ and $\mathrm{LH}$ were $0.1^{\circ} \mathrm{C}$ higher than that of HL $(P<0.05)$.

\section{DISCUSSION}

The objective of the experiment was to test the effect of offering rations that differed both in fiber and fermentable starch during the high intake or low intake periods of the day. Steam-flaked corn and corn
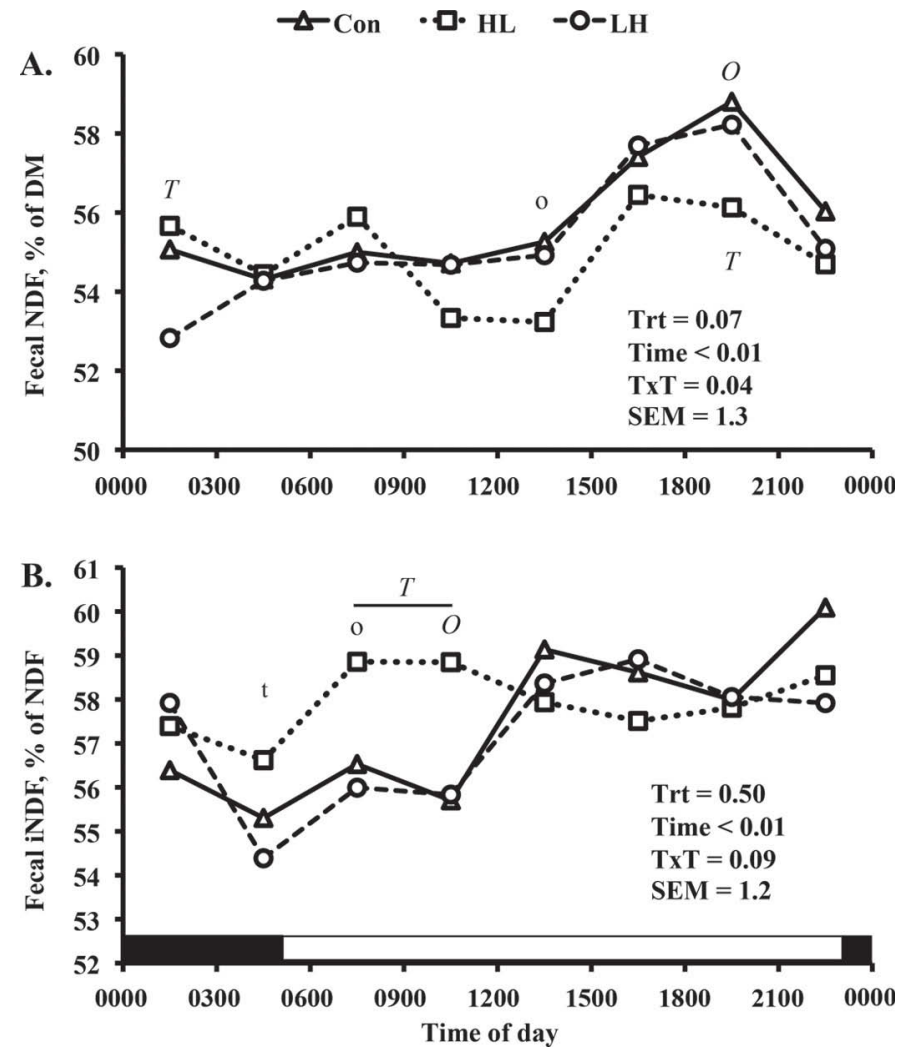

Figure 2. The effect of feeding a single TMR or feeding 2 rations within a day that differ in fiber and fermentable starch concentration on the daily rhythm of fecal NDF and indigestible NDF (iNDF) concentrations. Control (Con) was fed a TMR that was a 1:3 mix of a low fiber and high fermentable starch ration (LFHS) and high forage and low fermentable starch ration (HFLS) at $0700 \mathrm{~h}$, the high/low treatment (HL) was fed HFLS at $75 \%$ of daily offering at $0700 \mathrm{~h}$ and a LFHS ration at $25 \%$ of daily offering at $2200 \mathrm{~h}$, and the low/high treatment (LH) was fed LFHS ration at $25 \%$ of daily offering at 0700 $\mathrm{h}$ and HFLS ration at $75 \%$ of daily offering at $1100 \mathrm{~h}$. The effects of treatment (Trt), time, and their interaction (TxT) are shown within the panel. Preplanned contrasts tested the difference between $\mathrm{CON}$ and HL $\left({ }^{O} P<0.05\right.$, and $\left.{ }^{\circ} P<0.1\right)$, and between HL and LH $\left({ }^{T} P<\right.$ 0.05 , and $\left.{ }^{\mathrm{t}} P<0.1\right)$. Light and dark phases are shown. 
Table 4. The effect of feeding 2 rations within a day that differ in fiber and starch concentration and fermentable starch concentration on feeding behavior

\begin{tabular}{|c|c|c|c|c|c|c|c|c|}
\hline \multirow[b]{2}{*}{ Meal } & \multirow[b]{2}{*}{ Ration } & \multicolumn{2}{|c|}{ Treatment mean $^{1}$} & \multirow[b]{2}{*}{ SEM } & \multicolumn{4}{|c|}{$P$-value ${ }^{2}$} \\
\hline & & HL & $\mathrm{LH}$ & & Trt & Ration & Trt $\times$ ration & HL vs. LH \\
\hline Size, kg/meal & HFLS & 2.5 & 2.4 & & & & & 0.74 \\
\hline \multirow{2}{*}{ Length, min/meal } & LFHS & 40.2 & 46.7 & 1.9 & 0.02 & $<0.01$ & 0.30 & 0.02 \\
\hline & HFLS & 33.5 & 36.1 & & & & & 0.34 \\
\hline Interval, min & LFHS & 132.4 & 65.6 & 17.0 & 0.03 & 0.30 & $<0.01$ & $<0.01$ \\
\hline
\end{tabular}

${ }^{1}$ Least squares means. Control (CON) was fed a TMR that was a 1:3 mix of a low fiber and high fermentable starch ration (LFHS) and high forage and low fermentable starch ration (HFLS) ration at $0700 \mathrm{~h}$, the high/low treatment (HL) was fed HFLS at $75 \%$ of daily offering at 0700 $\mathrm{h}$ and a LFHS ration at $25 \%$ of daily offering at $2200 \mathrm{~h}$, and the low/high treatment (LH) was fed LFHS ration at $25 \%$ of daily offering at 0700 $\mathrm{h}$ and HFLS ration at $75 \%$ of daily offering at $1100 \mathrm{~h}$.

${ }^{2}$ Trt $=$ treatment effect; ration $=$ effect of ration; and Trt $\times$ ration $=$ treatment by ration interaction; HL vs. LH $=$ preplanned contrast.

silage were used as the starch and forage source in the LFHS, as they contain more rapidly fermented starch compared with dry ground corn. The LFHS ration was offered at $25 \%$ of daily feed offering and the HFLS ration at $75 \%$ of daily feed offering in both HL and $\mathrm{LH}$ treatments. The goal of the HL treatment was to equalize the amount of fermentable substrate entering the rumen across the day by feeding a high fiber and

$\triangle$ Con $\quad \cdot \square \cdot$ HL $\quad$-O-LH
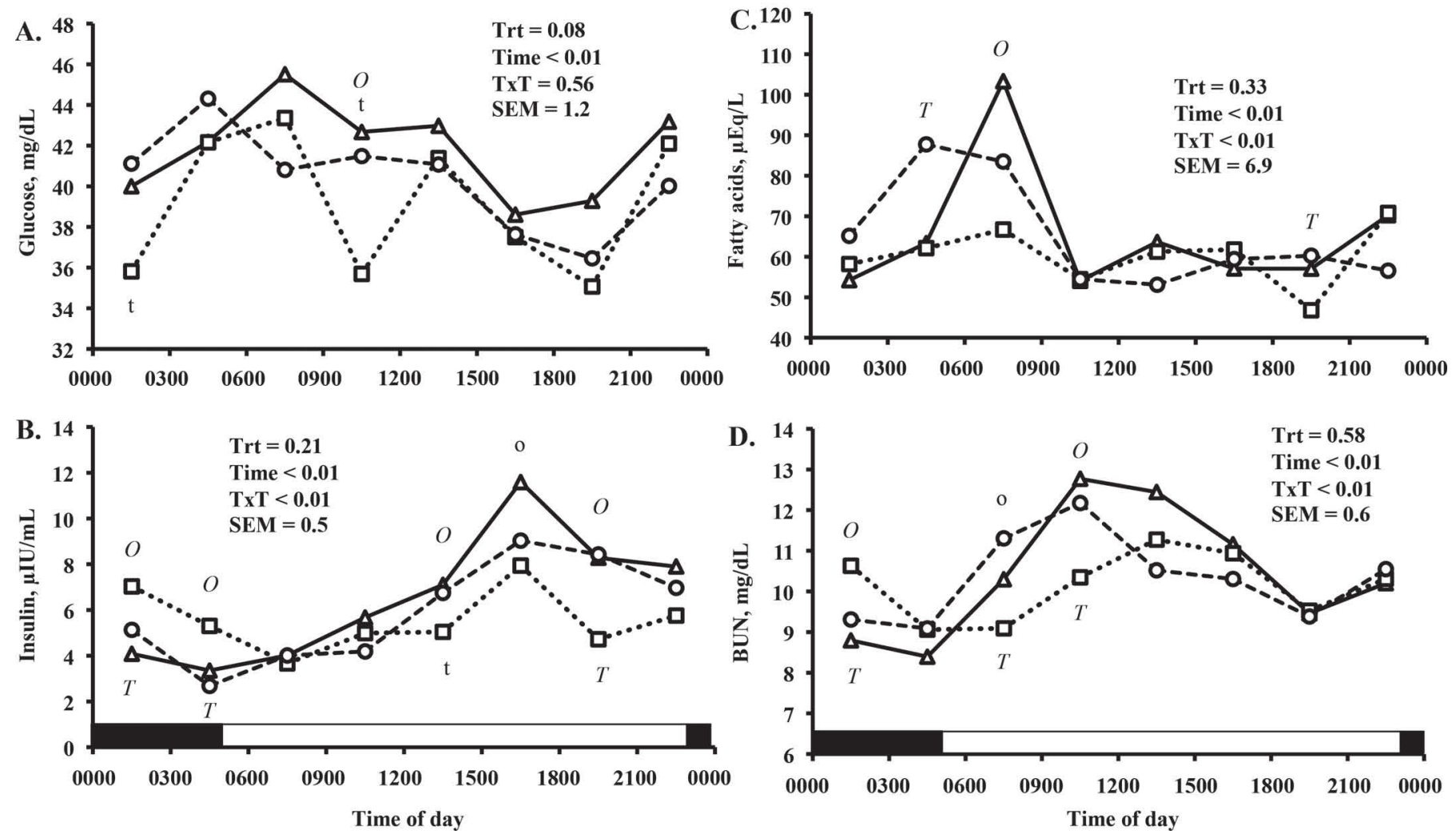

Figure 3. The effect of feeding a single TMR or feeding 2 rations within a day that differ in fiber and fermentable starch concentration on the daily rhythm of plasma glucose (A), insulin (B), fatty acids (C), and BUN (D) concentration. Control (Con) was fed a TMR that was a 1:3 mix of a low fiber and high fermentable starch ration (LFHS) and high forage and low fermentable starch ration (HFLS) at 0700 h, the high/low treatment (HL) was fed HFLS at $75 \%$ of daily offering at $0700 \mathrm{~h}$ and a LFHS ration at $25 \%$ of daily offering at $2200 \mathrm{~h}$, and the low/high treatment (LH) was fed LFHS ration at $25 \%$ of daily offering at $0700 \mathrm{~h}$ and HFLS ration at $75 \%$ of daily offering at $1100 \mathrm{~h}$. The effect of treatment (Trt), time, and their interaction (TxT) are shown within the panel. Preplanned contrasts tested the difference between CON and HL $\left({ }^{O} P<\right.$ 0.05 , and $\left.{ }^{\circ} P<0.1\right)$, and between HL and LH $\left({ }^{T} P<0.05\right.$, and $\left.{ }^{t} P<0.1\right)$. Light and dark phases are shown above the $\mathrm{x}$-axis in panels $\mathrm{B}$ and $\mathrm{D}$. 


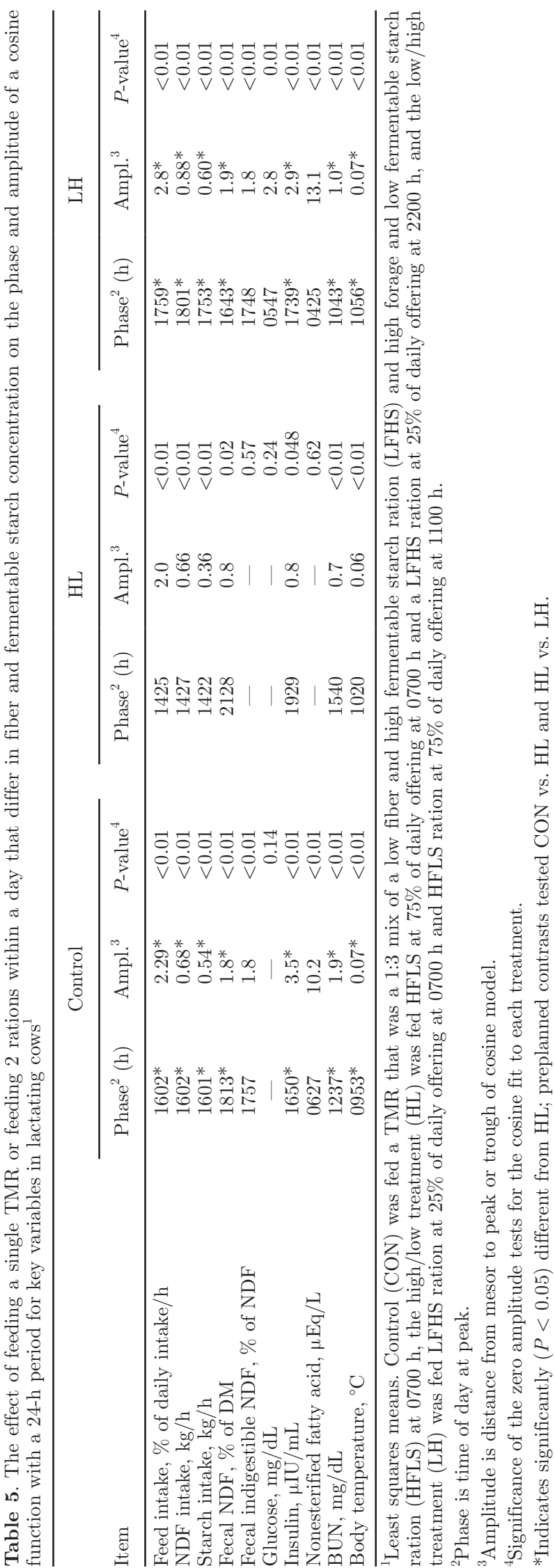

low fermentable starch ration during the high intake period of the day and a low fiber and high fermentable starch ration during the lower intake period of the day. The LH treatment was expected to do the opposite as it increased the amount of fermentable substrate entering the rumen during the high intake period of the day. However, Rottman et al. (2015) reported that a feeding strategy similar to LH increased feed efficiency and milk fat yield compared with a ration similar to HL, presumably because of a priming effect allowing a more rapid increase in rumen starch from the low levels during the overnight.

The dairy cow generally has a low rate of feed intake during the overnight and early morning periods of the day and a moderate rate of intake rate in the early afternoon as reported by others under different feeding schedules (e.g., DeVries et al., 2003, 2005; DeVries and von Keyserlingk, 2005). Additionally, offering fresh feed is a strong stimulus for intake (DeVries and von Keyserlingk, 2005). A similar overall intake pattern and stimulation by feeding was observed in the current experiment. It is noteworthy that the feed intake observation stalls are sequentially located next to each other and treatment sequences were randomly assigned to stalls. Therefore, there is the potential for stimulation of feeding in cows when other cows are offered fresh feed. In other experiments we have observed minimal effect, but some stimulation may have occurred. Therefore, increases in intake when other diets were fed may be conditioned by activity within the barn and not represent spontaneous behavior. However, random assignment is required to not confound treatment with position with barn.

Treatments modified feeding pattern over the day. The HL treatment reduced the feed intake at the morning conditioned meal after feeding and spontaneous intake tended to be reduced during the afternoon and was reduced before the evening feeding. The high forage ration may have resulted in physical fill limitation of intake during the high intake period of the day. Nikkhah et al. (2008) and Niu et al. (2014) also reported higher rates of feed intake after feeding a TMR in the evening. Compared with the morning feeding, night feeding of the LFHS ration may have similarly shifted the circadian pattern of intake. The LFHS ration was consumed at a higher rate after feeding than the HFLS ration regardless of feeding time, which may be due to the smaller particle size and reduced gut filling effect of the ration or palatability (Table 1). The LFHS ration is expected to result in more propionate production that would decrease intake based on the hepatic oxidation theory (Allen et al., 2009), but this mechanism did not appear to have an effect in the current experiment. Feeding the LFHS in the morning 


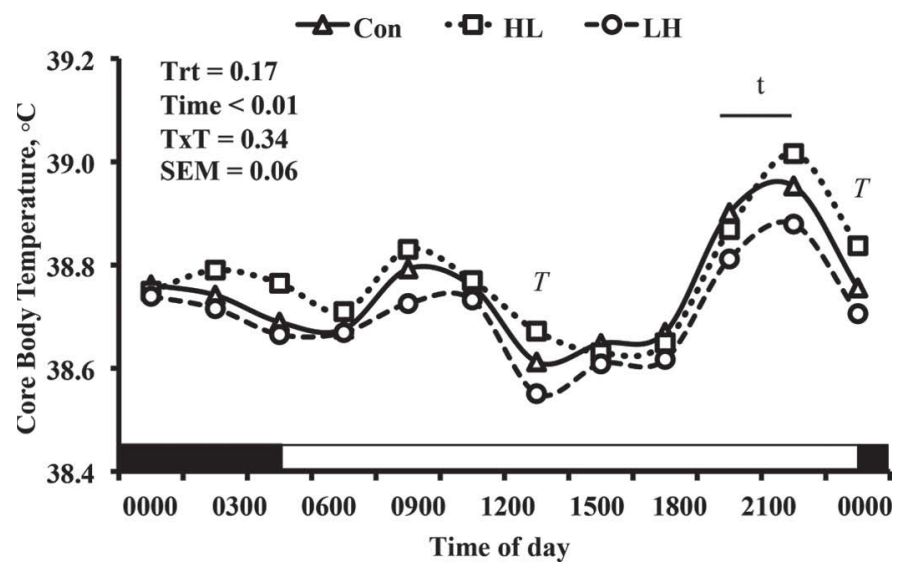

Figure 4. The effect of feeding a single TMR or feeding 2 rations within a day that differ in fiber and fermentable starch concentration on the daily rhythm of body temperature over 2-h intervals. Control (Con) was fed a TMR that was a 1:3 mix of a low fiber and high fermentable starch ration (LFHS) and high forage and low fermentable starch ration (HFLS) at $0700 \mathrm{~h}$, the high/low treatment (HL) was fec HFLS at $75 \%$ of daily offering at $0700 \mathrm{~h}$ and a LFHS ration at $25 \%$ of daily offering at $2200 \mathrm{~h}$, and the low/high treatment (LH) was fed LFHS ration at $25 \%$ of daily offering at $0700 \mathrm{~h}$ and HFLS ration at $75 \%$ of daily offering at $1100 \mathrm{~h}$. The effect of treatment (Trt), time, and their interaction (TxT) are shown within the panel. Significant preplanned contrasts between HL and LH $\left({ }^{T} P<0.05\right.$, and $\left.{ }^{t} P<0.1\right)$ are shown. Light and dark phases are shown.

may not have increased propionate absorption above a threshold required for stimulation of satiety because of lower expected rumen propionate concentrations and lower hepatic fuel availability in the morning. The LFHS was expected to decrease intake when fed in the evening because of the high fuel availability during this period. However, cows rapidly consumed the diet and may not have allowed time feedback regulation. The HL treatment was successful in reducing starch intake early in the day, but the large amount of starch consumed in the evening is not ideal and may result in rumen acidosis in some conditions. Although not measured in the current study, the HL treatment does not appear to have caused altered rumen biohydrogenation, a common result of acidosis.

Rumen fermentation was not directly characterized in the current experiment, but milk and milk fat yield, total-tract digestibility, and fecal NDF and iNDF provide insight into changes in rumen function. The concentration of fecal NDF and iNDF is an indicator of rumen outflow and was reported to be influenced by TMR particle size (Maulfair et al., 2011) and may also be affected by gut fill, rumination, gut motility, ruminal retention time, and dietary associative effects (Allen, 1997). Accordingly, the observed changes in the circadian rhythm of fecal NDF and iNDF concentration demonstrate a modification of rumen function, although identifying the specific cause was not within the scope of the current experiment. Niu et al. (2014) previously reported that the concentration of fecal NDF and iNDF exhibited a daily rhythm that was modified by feeding time. Interestingly, in the present experiment, a daily rhythm of fecal NDF and iNDF was only detected for CON and LH, which may indicate that HL was successful in stabilizing rumen outflow across the day. However, daily digested amount and total-tract digestibility of DM, OM, and NDF did not differ between the feeding regimens.

A reduction in both milk fat percentage and milk fat yield were observed in cows fed a low fiber and high fermentable starch ration during the high intake period of the day and a high fiber and low fermentable starch ration over the low intake period of the day. Furthermore, this depression of milk fat mostly occurred during the morning milking (0.32 percentage units lower for $\mathrm{LH}$ compared with HL). Milk fat synthesis is decreased when feeding high concentrate and low fiber ration and can reduce milk fat yield by up to $50 \%$ because of synthesis of bioactive fatty acid intermediates of ruminal unsaturated fatty acid biohydrogenation (reviewed by Bauman and Griinari, 2003). Trans-11 C18:1 and cis-9,trans-11 CLA are intermediates in the normal rumen biohydrogenation pathway, but their concentrations are also increased as rumen fermentation is altered in the early stages of milk fat depression (reviewed by Bauman and Griinari, 2003; Harvatine et al., 2009). The tendency for an increase in trans-11 C18:1 and cis-9,trans-11 CLA in LH compared with HL treatment indicates a decrease in the rate or capacity of the final steps of the normal ruminal biohydrogenation pathway. Although an increase in the intermediates of the alternate pathway was not observed, the change may be below the level of detection or may be explained by other bioactive intermediates. Rottman et al. (2015) reported that the lowest period of milk fat synthesis occurred during the night when cows were milked every $6 \mathrm{~h}$. It is expected that the synchronization of rhythms in nutrient absorption and milk synthesis is important in maximizing feed efficiency. The increased milk fat at the morning milking in the HL treatment may be explained by asynchrony of rhythms of nutrient availability and milk fat synthesis in the mammary gland or shifts in the diurnal rhythm of milk fat synthesis. Sheperd and Combs (1998) observed increased milk fat synthesis with infusion of acetate and the increased feed intake in the late evening may have provided more acetate for milk fat synthesis during the night.

The concentration of plasma glucose is directly related to timing of feed intake and is influenced by hepatic gluconeogenesis, glucagon, and insulin. Oba and Allen (2003) reported that plasma glucose declined after feeding and reached a nadir approximately $4 \mathrm{~h}$ after feed- 
ing. In the current experiment, a similar postfeeding decrease of plasma glucose was observed in CON and LH, but HL had a decrease in plasma glucose after each of the 2 feedings.

Plasma fatty acids, insulin, and BUN are commonly reported to exhibit a daily rhythm (Lefcourt et al., 1999; Giannetto and Picciano, 2009). Plasma fatty acids are an indicator of energy balance and increased plasma fatty acids normally occur during the overnight low intake period, indicating lipid mobilization to meet energy demands. The timing of feed intake, especially intake of RDP, is the main driver of BUN concentration, and changing the timing of feed intake changed the daily rhythm of BUN (Niu et al., 2014). Last, insulin normally increases during the high intake period of the day as a result of the high rate of nutrient absorption and decreases during the low intake overnight period. In the current experiment, $\mathrm{CON}$ and $\mathrm{LH}$ followed the expected pattern for fatty acids, insulin, and BUN, but HL resulted in a loss of fatty acid rhythmicity and a decrease in the amplitude of insulin and BUN. Taken together, this observation provides strong support for a more consistent daily rhythm of entry of substrate into the rumen, rumen fermentation, and nutrient absorption.

Body temperature is commonly used as an indicator of the phase of the underlying biological clock (Klerman et al., 2002) and a daily rhythm of body temperature has been reported in dairy cows (Giannetto and Picciano, 2009). Additionally, we previously reported that the circadian rhythm of body temperature was responsive to feeding time in Niu et al. (2014). In the current study, the acrophase and amplitude of body temperature were modified by HL compared with the CON and LH treatments; therefore, it appears that HL modified the central circadian clock. The central clock is normally predominantly regulated by light and dark cycles and indicates a large role for the timing of nutrient intake in the circadian regulation of the cow.

\section{CONCLUSIONS}

Feeding a low fiber and high fermentable starch ration during the high intake period of the day had little effect on daily intake or milk production; however, feeding a low fiber and high fermentable starch ration during the low intake period decreased milk fat concentration and yield. Feeding a low forage and high fermentable starch ration during the low intake period of the day increased the conditioned meal and postfeeding insulin secretion and resulted in the loss of fatty acids and glucose rhythmicity and a decrease in the amplitude of the rhythm of insulin and BUN. Feeding 2 TMR with different fiber levels and starch fermentability may modify the daily rhythm of rumen fermentation; specifically, feeding a low fiber and high fermentable starch ration at night may stabilize nutrient absorption over the day, but the effect of the diet and feeding time on the daily pattern of feed intake must be considered. Modification of other dietary factors across the day may improve rumen function and milk synthesis and provides a rich area for future research.

\section{ACKNOWLEDGMENTS}

The authors gratefully acknowledge the technical assistance of Andrew Clarke, Jared Risser, D. E. Rico, Liying Ma, Kan Zhou, and Natalie Urrutia (Penn State University, University Park). Gratitude is also expressed to the Pennsylvania State University Dairy Cattle Research and Education Center. Research supported in part by USDA Special Grant 2009-3428120116 (PI Harvatine), Agriculture and Food Research Initiative Competitive Grant no. 2010-65206-20723 and 2015-67015-23358 from the USDA National Institute of Food and Agriculture, and Penn State University.

\section{REFERENCES}

Allen, M. S. 1997. Relationship between fermentation acid production in the rumen and the requirement for physically effective fiber. J. Dairy Sci. 80:1447-1462.

Allen, M. S., B. J. Bradford, and M. Oba. 2009. Board invited review: The hepatic oxidation theory of the control of feed intake and its application to ruminants. J. Anim. Sci. 87:3317-3334.

Ballou, M. A., R. C. Gomes, S. O. Juchem, and E. J. DePeters. 2009. Effects of dietary supplemental fish oil during the peripartum period on blood metabolites and hepatic fatty acid compositions and total triacylglycerol concentrations of multiparous Holstein cows. J. Dairy Sci. 92:657-669.

Bauman, D. E., and J. M. Griinari. 2003. Nutritional regulation of milk fat synthesis. Annu. Rev. Nutr. 23:203-227.

Coppock, C. E., D. L. Bath, and B. J. Harris. 1981. From feeding to feeding systems. J. Dairy Sci. 64:1230-1249.

DeVries, T. J., and M. A. von Keyserlingk. 2005. Time of feed delivery affects the feeding and lying patterns of dairy cows. J. Dairy Sci. 88:625-631.

DeVries, T. J., M. A. von Keyserlingk, and K. A. Beauchemin. 2003. Short communication: Diurnal feeding pattern of lactating dairy cows. J. Dairy Sci. 86:4079-4082.

DeVries, T. J., M. A. G. von Keyserlingk, and K. A. Beauchemin. 2005. Frequency of feed delivery affects the behavior of lactating dairy cows. J. Dairy Sci. 88:3553-3562.

Fickett, F. M., and M. S. Allen. 2002. Ruminal fluid effects on in vitro digestion kinetics of corn starch. J. Dairy Sci. 85S:181.

Giannetto, C., and G. Picciano. 2009. Daily rhythms of 25 physiological variables in Bos taurus maintained under natural conditions. J. Appl. Biomed. 7:55-61.

Harvatine, K. J., and M. S. Allen. 2006. Effects of fatty acid supplements on feed intake, and feeding and chewing behavior of lactating dairy cows. J. Dairy Sci. 89:1104-1112.

Harvatine, K. J., Y. R. Boisclair, and D. E. Bauman. 2009. Recent advances in the regulation of milk fat synthesis. Animal 3:40-54.

Karkalas, J. 1985. An improved enzymatic method for the determination of native and modified starch. J. Sci. Food Agric. 36:1019 1027 . 
Klerman, E. B., H. B. Gershengorn, J. F. Duffy, and R. E. Kronauer. 2002. Comparisons of the variability of three markers of the human circadian pacemaker. J. Biol. Rhythms 17:181-193.

Lefcourt, A. M., J. Bitman, D. L. Wood, and R. M. Akers. 1995 Circadian and ultradian rhythms of peripheral growth hormone concentrations in lactating dairy cows. Domest. Anim. Endocrinol. 12:247-256.

Lefcourt, A. M., J. B. Huntington, R. M. Akers, D. L. Wood, and J. Bitman. 1999a. Circadian and ultradian rhythms of body temperature and peripheral concentrations of insulin and nitrogen in lactating dairy cows. Domest. Anim. Endocrinol. 16:41-55.

Lefcourt, A. M., J. B. Huntington, R. M. Akers, D. L. Wood, and J. Bitman. 1999b. Circadian and ultradian rhythms of body temperature and peripheral concentrations of insulin and nitrogen in lactating dairy cows. Domest. Anim. Endocrinol. 16:41-55.

Maulfair, D. D., M. Fustini, and A. J. Heinrichs. 2011. Effect of varying total mixed ration particle size on rumen digesta and fecal particle size and digestibility in lactating dairy cows. J. Dairy Sci. 94:3527-3536.

Nikkhah, A., C. J. Furedi, A. D. Kennedy, G. H. Crow, and J. C. Plaizier. 2008. Effects of feed delivery time on feed intake, milk production, and blood metabolites of dairy cows. J. Dairy Sci. 91:4249-4260.

Niu, M., Y. Ying, P. A. Bartell, and K. J. Harvatine. 2014. The effects of feeding time on milk production, total-tract digestibility, and daily rhythms of feeding behavior and plasma metabolites and hormones in dairy cows. J. Dairy Sci. 97:7764-7776.

NRC. 2001. Nutritional Requirements of Dairy Cattle. 7th rev. ed. Natl. Acad. Sci., Washington, DC.

Oba, M., and M. S. Allen. 2003. Effects of corn grain conservation method on feeding behavior and productivity of lactating dairy cows at two dietary starch concentrations. J. Dairy Sci. 86:174183.

Rico, D. E., and K. J. Harvatine. 2013. Induction of and recovery from milk fat depression occurs progressively in dairy cows switched between diets that differ in fiber and oil concentration. J. Dairy Sci. 96:6621-6630.

Rottman, L. W., Y. Ying, K. Zhou, P. A. Bartell, and K. J. Harvatine. 2014. The daily rhythm of milk synthesis is dependent on the timing of feed intake in dairy cows. Physiol. Rep. 2:e12049. http:// dx.doi.org/10.14814/phy2.12049.

Rottman, L. W., Y. Ying, K. Zhou, P. A. Bartell, and K. J. Harvatine. 2015. The effects of feeding rations that differ in neutral detergent fiber and starch concentration within a day on production, feeding behavior, total-tract digestibility, and plasma metabolites and hormones in dairy cows. J. Dairy Sci. 98:4673-4684.

Schibler, U., J. Ripperger, and S. A. Brown. 2003. Peripheral circadian oscillators in mammals: Time and food. J. Biol. Rhythms 18:250-260.

Sheperd, A. C., and D. K. Combs. 1998. Long-term effects of acetate and propionate on voluntary feed intake by midlactation cows. J. Dairy Sci. 81:2240-2250

Tolkamp, B. J., and I. I. Kyriazakis. 1999. To split behaviour into bouts, log-transform the intervals. Anim. Behav. 57:807-817.

Ying, Y., L. W. Rottman, C. Crawford, P. A. Bartell, and K. J. Harvatine. 2015. The effects of feeding rations that differ in neutral detergent fiber and starch concentration within a day on rumen digesta nutrient concentration, $\mathrm{pH}$, and fermentation products in dairy cows. J. Dairy Sci. 98:4685-4697. 